\title{
Transport Coopetition for Environmental Sustainability: Guiding Vertical Standard Design
}

\author{
Rikard Lindgren \\ University of Gothenburg \\ rikard.lindgren@ituniv.se
}

\author{
Jens Holgersson \\ University of Borås \\ jens.holgersson@hb.se
}

\begin{abstract}
IS researchers have so far developed conceptual propositions rather than empirical insights into what it takes to green an industry in practice. This paper analyzes an ongoing ten-year action design research effort, which seeks to leverage transport coopetition for environmental sustainability by guiding vertical standard design. Drawing on extensive field data, the paper theorizes about design challenges that surround attempts to tie together people, technologies, and processes into integrated IT solutions. In doing so, it illustrates the usefulness of a coopetitive lens for understanding these challenges and their effects on the evolution of such solutions. The paper also suggests that the action design research approach helps IS researchers to guide technology development in realworld situations.
\end{abstract}

\section{Introduction}

Recently, increased attention has been paid to the role information technology might play in improving environmental sustainability [9, 23]. IS researchers frequently argue that the development of integrated systems that allow heterogeneous supply chain actors to share information and coordinate actions is a prerequisite for promoting more environmentally conscious behavior [36, 37]. Thus far, research contributions have been primarily conceptual in nature, offering propositions rather than empirical insights about what it takes to green an industry in practice.

To enrich the IS literature, this paper addresses the issue of how information infrastructures may leverage flexible inter-organizational partnerships that support environmentally sustainable business practices. Given that such infrastructures comprise heterogeneous actors and technologies [37], vertical standardization is a central issue. Vertical standards - open specifications for integrating and digitalizing business processes in an industry - enable user organizations and competing vendors of technology to collectively develop information infrastructures [3, 20, 22, 35].
Collaboration between stakeholders of different structural types, typically having diverging interests, is key to environmentally sustainable business practices. In this context, however, one pressing issue concerns the establishment of coopetition among organizations, leading to concurrent collaboration and competition $[11,13,30]$. Vertical standards initiatives are excellent milieus for advancing the current understanding of coopetition in efforts for environmental sustainability.

This paper is motivated by the lack of knowledge about the design of vertical standards aimed at enabling coopetition for environmentally sustainable business practices. Focusing on coopetition between firms involved in attempts to assemble heterogeneous technologies through vertical standardization, we seek to address the following research question: How and why does vertical standard design help leverage coopetition that promotes environmentally sustainable business practices?

The paper analyzes an ongoing ten-year action design research effort [26] on the development and diffusion of a vertical standard whose purpose is to seamlessly integrate the actors and technologies that constitute the Swedish road haulage industry. By aligning the array of proprietary and incompatible embedded, mobile, and stationary IT systems that proliferate the industry $[1,18]$, the standard is expected to enable environmentally sustainable transport practices such as load sharing across firms, route optimization, and the monitoring of driver behavior [2]. From the outset, powerful representatives of road haulage firms, truck manufacturers, and system integrators were committed to the standard and its green objectives. Divergence in commercial interests, organizing visions, and design preferences, however, posed considerable challenges to the change effort.

Drawing on extensive field data, we develop a process account of coopetition that explains how and why vertical standard design may lead to concurrent cooperative and competitive actions that promote environmentally sustainable business practices. Our analysis reveals how different stakeholders' interests evolved from a competitive/market focus to a 
coopetitive/ecosystem perspective. That is, their interests became increasingly green over time, thereby boosting the potential for environmentally sustainable transport practices to emerge.

This paper makes two distinct contribution to the IS literature on environmental sustainability. First, it illuminates the challenges created by the sociotechnical complexities that arise when attempting to tie together people, technologies, and processes into integrated IT solutions supportive of environmental sustainability. Second, we illustrate the usefulness of a coopetitive lens for understanding these challenges and their effects on the evolution of such solutions. In addition, the paper also reflects upon real-world situations where action design researchers seek to guide the development of new technology so that it meets human needs.

\section{Theoretical Review}

\subsection{Environmental Sustainability}

The IS discourse on environmental sustainability has so far primarily dealt with the role of IT in attempts to reduce energy consumption $\left(\mathrm{CO}_{2}\right)$. Building on the Belief-Action-Outcome framework, Melville [23] offers a research agenda on IT innovation for environmental sustainability. It focuses on informing beliefs, enabling actions, and transforming outcomes, and calls for IS research on incentive structures, systems modeling, and integrated assessment.

Elliot [9] proposes an impact-oriented, transdisciplinary, and multifaceted conceptual model for business transformation. It categorizes the environment and five types of stakeholders as separate yet interactive systems within a single ecosystem. In the same vein, Watson et al [36] develop a new IS perspective, energy informatics, that concerns the analysis, design, and implementation of IT to increase the efficiency of energy demand and supply systems. The underlying idea is that energy plus information equals less energy, which requires a common information system that spans supply and demand. This invites to a single system approach to environmental sustainability.

Further, Watson et al [36] suggest that three types of technology components should be present in an intelligent energy system: flow networks, sensor networks, and sensitized objects. An information system ties together the various components to provide an integrated IT solution supportive of environmental sustainability. Such a system can be deployed to achieve three broad sustainability goals: ecoefficiency, eco-equity, and eco-effectiveness.
Successful integration of a set of heterogeneous technologies is a prerequisite for environmentally sustainable business processes involving interactions between different actors [37]. The single system approach suggested by Watson et al [36] represents a means to leverage such socio-technical connectivity. However, their approach is mostly theoretical, and they adopt an overly simplistic view of how to develop integrated IT solutions. Little is said about the fact that such development entails novel changes in individual and collective socio-technical capabilities, which in turn create a high degree of uncertainty. As a response, our analysis shows that vertical standardization for environmental sustainability unfolds as a non-linear, emergent, and path-dependent process, involving complex design, negotiation, and sensemaking events.

\subsection{Vertical Standardization}

We view vertical standards as a particular class of information systems [22]. Such standards prescribe data structures and definitions, document formats, and business processes for particular industries $[20,35]$. Bala and Venkatesh [3, p. 341] note that conceptual standards "not only specify and define the structure and format of business messages through a common language but also orchestrate the message exchange choreography, i.e., sequence of steps required to execute an atomic business process among trading partners". Such standards thus serve to describe procedures and practices that should be followed to achieve a desired outcome.

Vertical standards embody specific collaboration needs of a certain industry or groups of organizations. The variety of the technologies and stakeholders involved constitutes a complex and rapidly changing environment. However, such initiatives need to encompass heterogeneous groups of IT vendors and user organizations without fragmenting. Vertical standardization efforts that evolve into rival, homogeneous groups are less likely to develop a standard that wins industry acceptance.

Industry consortia or forums are therefore established to coordinate the implementation of standards in the marketplace by swiftly exploiting commercial possibilities. As the anatomy of a consortium reflects the stakeholders of the standard developed, it relates to the value networks embedded in the industry in question. Recent examples of industry standard initiatives include CIDX in chemicals, FIX in financial services, MISMO in mortgage, PIDX in petroleum, and RosettaNet in electronics.

Extant IS research has addressed collective action dilemmas in vertical standards development and diffusion [22], assimilation of vertical standards in 
organizations [3], extended enterprise arrangements enabled by vertical standards [20], and industry effects of vertical standardization [35]. These studies offer a solid understanding of how and why vertical standards emerge and diffuse. However, to our knowledge, there is no prior IS research that specifically explores design challenges in vertical standard development aimed at enabling environmental sustainability through the establishment of coopetition.

\subsection{Coopetitive Action}

Coopetition is a reasonably new concept coined for framing situations in which collaboration and coopetition occur simultaneously [25]. It breaks with the classical assumption that relationships between firms are either competitive or cooperative in nature [32]. Viewing competition and collaboration as a duality rather than a dualism, however, has proven to be a powerful strategy for theorizing collective action in firm networks [30] as well as inter-firm networks [5].

Given the direction of our paper, it should be noted that standard development in most situations involves concurrent competition and collaboration [22]. Indeed, the success of a standard is often a result of collaboration between different stakeholders that both compete and complement each other. Once gaining momentum, enrollment of new actors to the network makes the standard stronger.

The history of standards development, however, suggests that many initiatives fail as a result of coopetitive relationships being competition-dominant [5]. As Garud et al [11, p. 198] note, "cooperation among members of a standards collective is uneasy at best" and that "inducing and maintaining such a collective is a challenge even for a neutral body". This observation begs the question whether coopetition can be leveraged by vertical standard design so that environmentally sustainable business practices are promoted.

\subsection{Design Research}

The design of integrated IT solutions supportive of environmentally sustainable business practices usually involves many heterogeneous actors [36, 37]. Given the ambition to investigate how coopetition can be designed, it can be hypothesized that such design is not only about devising a common vertical standard with promising technical capabilities. Rather, as recent inter-firm standard innovation research [2] suggests, this is very much a socio-technical endeavor. Seeking to develop theories for design and action [12], it is natural to turn our attention to design research.

Design research is a paradigm directed towards design theory development through creating and evaluating innovative IT artifacts intended to solve identified organizational problems [16]. The outputs include not only instances of innovative artifacts but also knowledge about creating other instances that belong to this class [33].

Design research involves an iterative process covering problem awareness, artifact development, and evaluation. It does not emphasize interventions or deployments in authentic settings though. In fact, few IS design researchers have attempted to intervene directly in authentic settings (see Markus et al [21] for an exception), and human benefit is therefore at best a second-order goal.

Looking at a research methodology that places authentic intervention on the same page as theory generation, action research is an iterative process based on a working hypothesis refined over repeated cycles of inquiry [29]. Several action research methodologies exist. They vary across dimensions such as process model, structure, typical involvement, and primary goals [4]. Adopting different methodologies, most extant studies follow a social science tradition in that intervention is intended to gain insight into situated social phenomena (e.g., [24, 28]). In recent years, however, IS researchers have started to explore crossfertilization possibilities between action research and design research to leverage theory generation and researcher intervention for solving immediate organizational problems [7].

Henfridsson and Lindgren [14] and Lindgren et al [19] represent examples of design-oriented action research studies that develop knowledge contributions that theorize particular classes of IT artifacts. While the former study reports the building of a car connectivity solution to support mobile device use in multicontextual settings, the latter study offers design principles for competence management systems supportive of knowledge-intensive organizations that are embracing a core competence approach.

\section{Method}

\subsection{Research Setting}

The empirical setting of this paper is the Swedish road transport industry. Swedish road haulage firms are currently faced with increasing pressures to leverage their business propositions and operations at different points in the supply chain. To this end, they seek to implement different types of information systems as to improve their competitiveness. 
Broadly, there are three market segments of IT support in road transport: The stationary segment relies on desktop systems, servers, and e-business solutions as well as more traditional office automation, thus responding to the needs of transport management with managers and dispatchers as end-users; The mobile IT segment deals with mobile computing platforms that facilitate drivers' day-to-day work and communication; and the embedded IT segment deals with technologies embedded in vehicles, such as vehicle networks, RFID, and sensor technology, for improving the utilization of the fleet of vehicles and driver productivity.

Being small firms, Swedish road haulers rarely can afford to develop a custom built system as to secure sustainable practices. Rather, they are typically forced to consider the various off-the-shelf solutions available. The wide variety of business activities in road haulage firms makes this choice complicated.

\subsection{Research Design}

The paper reports an ongoing action design research project that was initiated in 2002 as to explore the design of information infrastructures aimed at environmentally sustainable transport practices. The project is a collaborative effort between University of Borås, University of Gothenburg, Viktoria Institute, and a large transport industry network. The industry network consists of 15 IT vendors, two truck manufacturers, and a consultative organization owned by 16 Swedish transport firms. In 2007 the involved actors formed the MSI Group (www.msigroup.se), which is a commercial consortium governing an interface standard (referred to as the MSI standard) that is now available to the Swedish road transport industry.

Since its genesis, representing the major system vendors and a sizeable part of the combined fleets in the Swedish transport industry, the industry network brought considerable transport system development experience covering all three IT segments (embedded, mobile, and stationary) to the project. The researchers initiated it, but once the Client-Researcher Agreement [8] was signed, the authority of the project was assigned to an action research team consisting of researchers and practitioners (responsible for communicating the negotiations and planning of action to their respective organizations). While the first author of this paper acts as the research manager for this ongoing study, the second author is the technical manager of the MSI standard.

Our research design reflects Sein et al's [26] action design research method, which "simultaneously aims at building innovative IT artifacts in an organizational context and learning from the intervention while addressing a problematic situation" (Sein et al. 2011, p.
38). It stresses the influence of the relevance cycle (Hevner 2007), and provides explicit guidance for combining building, intervention, and evaluation in a concerted research effort. The action design research method contains four stages (with associated principles) that encapsulate its underlying beliefs and values: 1) Problem Formulation; 2) Building, Intervention, and Evaluation; 3) Reflection and Learning; and 4) Formulation of Learning.

\subsection{Data Sources and Analysis}

Data covering the entire lifespan of the MSI standard were gathered from several different sources: interviews; board, project, and work meetings; workshops; e-mails; strategy and technical documents; system demonstrations; standard specifications; environmental reports; module, test case, and use case descriptions; press releases; and popular press articles.

The three main sources of data were: 1) Interviews with IT vendors, drivers, dispatchers, user organization managers, and transport industry representatives. The interviews covered different themes relevant to IT development and use in the road transport setting. 2) Project meetings involving key actors of the standardization effort. Typically chaired by the first author of this paper, the meetings were central to appreciate and address the coopetition challenges. Also, the material from these meetings was important sources for collecting data on the actions taken in the project. 3) Work meetings with client organizations (typically led by one of the members of the action research team). A series of prototype MSI standard interfaces were developed, and at these meetings IT vendors and user representatives provided their input and evaluative feedback. The resulting prototype interface was then subject to another iteration of feedback and subsequent development.

The overall data analysis strategy was designed to fit the nature of our research question. To this end, using our theoretical review as a sensitizing device [17], we coded the empirical material as to identify key issues related to IT integration problems and their antecedents as well as critical changes in the emerging MSI standard. We specifically sought to identify statements reflecting participants' reactions to important standard changes in order to draw out specific implications for the relationship between the research agenda and the divergent strategies of the participants [34]. Over cycles of deepened insight, our analysis was gradually geared towards classifying and generalizing the design activities that leveraged environmentally sustainable transport practices through the establishment of coopetition. 


\section{Findings}

\subsection{Problem Formulation}

IT-enabled stationary planning systems and mobile phones have for long played a significant role in road transport practice. However, at the time of the project genesis back in 2002, the general conception among Swedish road haulage firms was that emerging embedded and mobile technologies are potentially the vital means to leverage the inter-organizational coordination required to cope with the increasing competitive pressure in the road transport industry.

Fueled by trade press articles on the positive effects of the digital revolution for transport innovation, these firms anticipated that this next wave of digitization would allow for organizational and technological integration of people as well as the IT systems they use. Such socio-technical integration was seen as a prerequisite for effectively improving mobile resource evaluation, facilitating seamless transport data management, and rationalizing dispatcher-driver communication. Promoting an overly positive image of emerging digital opportunities, IT vendors and truck manufacturers alike sought to convince road haulage firms to believe these changes to represent the next step towards environmentally sustainable processes.

However, the media's construction of the digitization of Swedish road transport practice did include very few examples of successful organizational attempts to erect assemblages of embedded, mobile, and stationary technologies that have led to productivity gains. At industry conferences and seminars, representatives of the Swedish Road Haulage Association usually conveyed that the penetration of advanced distributed technology was still surprisingly low among their members. IT vendors pointing to the $\mathrm{R} \& \mathrm{D}$ investments on their part asserted that it was a matter of days before most road haulage firms would plunge into the new world of digital opportunities.

However, anecdotes from the road haulers themselves revealed that the continuous IT evolution had a somewhat darker side too. Efforts to implement interconnected infrastructures often faced complex hurdles because of the heterogeneous and distributed nature of involved technologies, organizations, and practices. Such socio-technical assemblages were apparently difficult to accomplish, and implementing firms felt that they wasted their money. Firms sharing their insights and war stories on integration difficulties had a damping impact on the overall willingness of road haulers to make proactive IT investments.

The net effect of what Swedish road haulage firms experienced as a "mobile-stationary divide" was nearly the stalled diffusion of new technology. Small road haulers' ability to productively utilize combinations of embedded, mobile, and stationary systems were restricted by at least three institutional forces. Truck manufacturers offered embedded systems that provided full support for their own brand only. Vendors of stationary systems offered technologies that were built on proprietary interfaces and standards. Contractors of haulers developed mobile and stationary IT systems intended to reinforce their information advantage. These institutional forces suggest that road haulage firms were locked-in by the proprietary strategies of dominating actors in the road transport industry.

Given the mobile-stationary divide, we carefully diagnosed the problems that road haulage firms experienced in their use of information infrastructures spanning organizational boundaries. We noted that fragmentation of existing technology solutions in terms of scope, as well as system vendor competence and interest, made it difficult for road haulers to build comprehensive information environments that addressed their needs. This fragmentation was manifested in a number of problems related to integration of heterogeneous systems. For example, road haulage firms were unable to evaluate truck performance via their PC-based fleet management systems because inclusion of vehicle sensor data such as fuel consumption was hindered by proprietary application interfaces.

The lack of standardized interfaces for integration of embedded, mobile, and stationary IT systems made it difficult for road haulage firms to realize environmentally sustainable transport solutions. The problem was traced to lack of knowledge sharing and collaboration between system vendors who served different industry segments. At this stage, an understanding of the socio-technical nature of coopetition emerged. In collaboration with the industry network, we developed a first definition of coopetition that would capture the nature of concurrent cooperative and competitive actions among organizational units in industry digitalization for environmentally sustainable transport practices: Information infrastructures comprise cooperative IT capabilities creating use contexts that evoke competitive business models.

\subsection{Building, Intervention, and Evaluation}

As the next step, the action research team decided to develop an interface standard as to instantiate the emergence and dynamics of coopetition among competing IT vendors and user organizations. Reviewing the proprietary interfaces of the involved firms, we developed an XML-interface standard that specified a common business language (terminology) 
for system-to-system communication of environmentally sustainable transport activities and their relationships. For example, sensor data from vehicle systems such as gearshift metrics, maintenance timing, and fuel consumption were included to supplement a stationary and goods-centered view of transport assignments. The MSI standard therefore enabled road haulage firms to simultaneously exchange information with multiple partners, which otherwise would have required extensive effort in one-to-one customization of information exchange parameters.

A team led by a researcher of the action research team and composed of technical staff at the participating organizations executed the design process. Over a series of iterations, the interface standard was revised to instantiate the emerging understanding of coopetition. The participating firms evaluated each release of the proposed standard by taking the interface to their development organizations for evaluation in light of their own proprietary interfaces and ongoing integration projects.

It became evident early on that sensor data of embedded systems in use were largely seen as a vendor resource, rather than the property of the user organization. Incorporating such data in the MSI standard threatened to make it available with considerably less effort than previously, thus making it available for service innovators primarily operating within other components (stationary or mobile). Worried about this new market logic, this prompted a hesitant stance from embedded vendors. Indeed, these negotiations were threatening to stall the entire process.

To permit a reconsideration of innovation potential and future business opportunities, customer pressure proved decisive. Such pressure could be leveraged by the consultative organization that conceptualized the inclusion of embedded systems data in terms of potential business relations. The conceptualization of business potential resulted in a compromise that allowed the inclusion of embedded data relevant to a transport assignment. While fuel consumption was included, it did not include high-resolution data used for other purposes such as vehicle maintenance and engine development. This arrangement provided vendors of embedded technology with what they considered an innovation leeway.

Following the design iterations, the interface standard was evaluated through three test integration cases and two authentic integration projects. The outcome of the former suggested that the MSI standard represents a substantial change from the existing approach to build interfaces across pairs of heterogeneous transport IT systems. Indeed, defining coopetition among competing firms, embedding it in the interface standard, and rethinking the roles needed from the member organizations all contributed to the IT artifact that was designed and emerged over multiple iterations. However, the authentic integration cases indicated that the MSI standard was too complex in terms of the information management opportunities it enabled. That is, the standard afforded firms the flexibility of customizing some parameters to adapt to their local requirements (emphasizing the formal language) at the expense of process descriptions that explain the use of them.

\subsection{Reflection and Learning}

Reflecting on the experiences from the two authentic implementation projects, the action research team learned that the local adaptability of the standard was perceived as a less productive feature. The MSI Group's subsequent modularization decision was a direct response to user firms' call for more structured integration guidance. As a consequence of the decision to modularize the MSI standard, the action research team was assigned the task of defining application areas to be enabled by it. That is, the standard would specify how embedded, mobile, and stationary IT systems should be integrated as to cater for central dimensions of environmentally sustainable fleet management. Indeed, the strategy to redesign the MSI standard to facilitate its further development and diffusion sparked new interest among actors in the Swedish road transport industry. For example, thirdparty technology vendors (e.g., route optimization) have joined the effort to develop a better understanding of how their IT components can become more attractive pieces in the innovation puzzle. In the current situation, the action research team is developing four distinct integration modules (each module is to be complemented with criteria to certify its implementation and diffusion):

First, the order-handling module is intended to serve as a facilitator of seamless transport data propagation. Addressing the collection and delivery of goods, this involves ensuring an unbroken and streamlined flow of information between distributed workers and office personnel. Such uninterrupted information sharing is necessary to make functionally, geographically as well as organizationally dispersed transport processes both effective and flexible but also environmentally sustainable.

Second, the embedded-measuring module is intended to enable spatially distributed devices (barcode, GPS, RFID etc.) to report status of a physical item or environmental condition. Making visible the consequences of patterns of action in a wide variety of field activities creates information about activities of 
human actors as well as information pertaining to trucks and associated hardware. Such information can be supplied to drivers to inform them about the distance they drive and the fuel they consume. It can also be used for mobile resource evaluation by allowing for analyses of vehicle-related elements such as idling time, oil pressure, and revolutions per minute. These and many other sources represent potential knowledge for eco-effective fleet management.

Third, the route-optimizing module is intended to facilitate collection of sensor data being automatically fed into route optimization algorithms coupled to backend planning systems. Such automated transfer of information means that the mobile context would be at hand at all times, allowing dispatchers to offer delivery schedules that can be changed if unexpected situations arise. For example, seeking the most efficient order of delivery, they can reroute a truck to avoid road construction. In addition, based on real time traffic information, a less congested route can be automatically recomputed for the truck's navigation system. Such route guidance is at the heart of successful eco-driving.

Fourth, the flexible-reporting module is intended to serve as an environmental impact report generator. To help user firms to compute a measure of the climate change impact of a transport operation, it will identify both available information items necessary to compute such a measure and information items that different actors can control. For example, knowing the fuel consumption of a truck, a fleet, a transport route, or a transport task, a manager can measure the climate change impact of a transport assignment. By measuring changes in controllable parameters and by calculating the resulting environmental performance, transport actors are allowed to better control the impact of their services.

\subsection{Formalization of Learning}

A distinct learning outcome of this study is that the participating organizations have deepened their understanding of how concurrent cooperative and competitive actions among organizational units can enable information infrastructure innovation for environmentally sustainable transport practices. Seeking to formalize our lessons learned into a general solution concept for a class of field problems, we offer a sequence of three design steps for managing a vertical standard design effort that aims at creating, maintaining, and leveraging coopetition for environmentally sustainable business practices.

First, our study suggests that it is of central importance to pursue an initial diagnosis that helps different stakeholders to appreciate how and why individual technologies can be integrated into an information infrastructure that effectively promotes environmentally sustainable business practices, and simultaneously generate new business opportunities through coopetition. The creation of such an understanding is necessary to facilitate architectural negotiations about how different types of standardsenabled infrastructure configurations promote and/or undermine individual stakeholders' environmental performance.

Second, following the initial diagnosis of the relationship between green behaviors and business possibilities, the next steps concerns the instantiation of design visions into a vertical standard. The standard should be designed so that it inscribes a viable coopetitive model reflective of the diverging interests of the participating actors. In this way, the standard can guide them in their attempts to measure and evaluate the environmental impact of business through the utilization of assemblages of technologies.

Third, our study highlights that the last step should seek to promote environmental sustainability purposes by innovating coopetitive business arrangements further. A key issue here is to adapt the vertical standard design for scalability so that new stakeholders can plunge into the development effort and erect infrastructures that cater for environmental responsibility in business operations.

\section{Discussion}

In line with prior IS research on environmental sustainability $[36,37]$ this paper recognizes that environmentally sustainable business practices require integrated IT solutions that cater for processes involving different stakeholders. Indeed, such supportive information infrastructures comprised of cooperative technologies can open novel avenues for collaborative linkages between competing firms, leading to coopetitive practices that build on concurrent collaboration and competition (cf. [5, 11, 13].

However, there are still many unanswered questions about the creation of information infrastructures aimed at leveraging environmentally sustainable business practices through the establishment of coopetition. One such question concerns the linkage between cooperative technologies, competitive actions, and environmental performance. Yet, we know little about the firm and network capabilities required to develop crossorganizational IT systems in settings dominated by competitive actions. A closely related question concerns the role of vertical standards in establishing 
green business arrangements that involve firms seeking ways to utilize cooperative technologies to strengthen their competitive ability. Our limited understanding of information infrastructures and coopetition can be traced to the scarcity of "green IS studies" that empirically explore the dynamics of IT-enabled coopetition. This is unfortunate given that knowledge about how digital systems may enable coopetitive practices is key for the future development of environmentally sustainable business in many domains.

Addressing this gap in the IS literature, the primary objective of this paper is to develop a process account of coopetition that explains how and why vertical standard design may lead to concurrent cooperative and competitive actions that promote environmentally sustainable business. Based on extensive field data, the paper has explored the emergence and dynamics of vertical standardization and coopetition in the Swedish road transport industry.

When this research was initiated, there were several unresolved socio-technical issues surrounding the design of information infrastructures capable of meeting the requirements of road haulage firms $[1,18]$. For example, interfaces between embedded, mobile, and stationary IT systems were usually proprietary, leading to lock-in effects that effectively undermined their attempts to erect infrastructures (indeed, many road haulers were reluctant to invest in nonstandardized solutions). A contributing factor was the rivalry and competition between different vendors of technology. Each vendor arguing that the best solution is to implement their full systems suite regardless of the vendor's core competence.

The lack of standardized interfaces for integration of embedded, mobile, and stationary IT systems effectively hampered road haulage firms to realize environmentally sustainable transport practices. While the utilization of proprietary interfaces created gaps between mobile and stationary socio-technical elements within road haulers, it also hindered such organizations to engage in multi-firm partnerships. In effect, it became difficult to reduce $\mathrm{CO}_{2}$ emissions by improving fleet utilization and implementing flexible logistics operations. Indeed, a key lesson learned was that the lack of a shared understanding of the relationship between cooperative technologies and competitive actions inhibited industry digitization for environmentally sustainable transport practices.

Given this problem situation, coopetition among competing IT vendors and user organizations had to be established to enable simultaneous cooperation and competition. The action research team developed a definition of coopetition that would capture the nature of concurrent cooperative and competitive actions among organizational units in industry digitalization for environmentally sustainable practices: Information infrastructures comprise cooperative IT capabilities creating use contexts that evoke competitive business models.

To embody the emergence and dynamics of coopetition among competing IT vendors and user organizations, it was decided that the project would develop a vertical standard. To make this feasible, an XML-based ontology of standardized concepts was negotiated, utilizing pre-existing standards where applicable. The resulting vertical standard was deemed better than the previous proprietary solutions when it comes to enabling environmentally sustainable transport solutions. However, the experiences with the standard point to important questions surrounding the design of information infrastructures supportive of coopetition.

As the empirical findings suggest, the required close collaboration between stakeholders complicated design decisions. The fact that data essential for transport organizations' remote diagnostics practices can also be used for product development purposes of the technology vendor rendered in a dispute. Access to context data provided by embedded technology thus proved to be a problematic issue. In fact, vendors of embedded technology were highly protective. Their repositories of raw context data were seen as potential for in-house innovation and future business opportunities. Therefore, access had to be negotiated through the establishment of specific use contexts and associated services utilizing specific sets of context data.

The negotiation of context resulted in a clear prescriptive way of creating exploitable representations specifying combinations of embedded, mobile, and stationary computing resources. However, only a limited set of context data was utilized due to the protective strategies of vendors of embedded technology. Progress was nonetheless evident as these were a product of a negotiation between the embedded, mobile, and stationary systems vendors, and user organizations, as opposed to determined by the vendors of the data acquiring technology. This indicates that the stakeholders' interests evolved from a competitive/market focus to a coopetitive/ecosystem perspective. That is, their interests became increasingly green over time, thus boosting the potential for environmentally sustainable transport practices to emerge. Our analysis suggests that the utilization of context data as perceived by end user organizations will be the result of a negotiation of viable usages. We believe that such commoditization of context data will continue to hamper the development of information infrastructures for coopetition. 
Reflecting on the design process, the emerging MSI standard served as a boundary object that allowed the actors to exchange knowledge embedded in practice [10]. Embodying the latest knowledge produced, the different versions of the standard enabled conversations by presenting representations of coopetitive practices. This is especially necessary when heterogeneous actors engage in design attempts to erect information infrastructures, because it is desirable that systems vendors and user organizations, while learning from each other, still maintain their own individual understanding (cf. [38]). Throughout the design process, the action research team played a critical role in translating, coordinating, and aligning different perspectives from multiple communities. Our involvement in this ongoing design agenda suggests the importance of IS researchers guiding design activities for human benefit [26].

The standard was meant for an industry and thus its use was shaped by the dynamics and objectives of the MSI group. The latter served as a forum where the future design of the artifact was negotiated and shaped through dialectic and compromise. Our case illustrates how practical efforts to erect standards-enabled infrastructures for coopetition may be organized so that industry networks with different innovation trajectories can negotiate, collaborate, and learn through perspective making and perspective taking. Indeed, we believe our proposed sequence of three design steps for managing a vertical standard design effort can help create, maintain, and leverage coopetition for environmentally sustainable business practices in many domains.

\section{References}

[1] Andersson, M. and Lindgren, R. "The Mobile-Stationary Divide in Ubiquitous Computing Environments: Lessons from the Transport Industry", Information Systems Management (22:4), 2005, pp. 65-79.

[2] Andersson, M., Lindgren, R. and Henfridsson, O. "Architectural Knowledge in Inter-Organizational IT Innovation", Journal of Strategic Information Systems (17:1), 2008, pp. 19-38.

[3] Bala, H. and Venkatesh, V. "Assimilation of Interorganizational Business Process Standards", Information Systems Research (18:3), 2007, pp. 340-362.

[4] Baskerville, R. L. and Wood-Harper, A. T. "Diversity in Information Systems Action Research Methods", European Journal of Information Systems (7:2), 1998, pp. 90-107.

[5] Bengtsson, M. and Kock, S. 2000. "Coopetition" In Business Networks - To Cooperate and Compete
Simultaneously, Industrial Marketing Management (29), 2000, pp. 411-426.

[6] Boland, R. J., Lyytinen, K. and Yoo, Y. "Wakes of Innovation in Project Networks: The Case of Digital 3-D Representations in Architecture, Engineering, and Construction", Organization Science (18:4), 2007, pp. 631647.

[7] Cole, R., Purao, S., Rossi, M. and Sein, M. K. "Being Proactive: Where Action Research Meets Design Research", In Proceedings of the Twenty-Sixth International Conference on Information Systems, Las Vegas, NV, 2005, pp. 325-336.

[8] Davison, R. M., Martinsons, M. G., and Kock, N. "Principles of Canonical Action Research", Information Systems Journal (14), 2004, pp. 65-86.

[9] Elliot, S. "Transdisciplinary Perspectives on Environmental Sustainability: A Resource Base and Framework for IT-Enabled Business Transformation", MIS Quarterly (35:1), 2011, pp. 197-236.

[10] Gal, U., Lyytinen, K. and Yoo, Y. "The Dynamics of It Boundary Objects, Information Infrastructures, and Organizational Identities: The Introduction of $3 \mathrm{~d}$ Modelling Technologies into the Architecture, Engineering, and Construction Industry", European Journal of Information Systems (17:3), 2008, pp. 290-304.

[11] Garud, R., Jain, S. and Kumaraswamy, A. 2002. "Institutional Entrepreneurship in the Sponsorship of Common Technological Standards: The Case of Sun Microsystems and Java", Academy of Management Journal (45:1), 2002, pp. 196-214.

[12] Gregor, S. "The Nature of Theory in Information Systems”, MIS Quarterly (30:3), 2006, pp. 611-642.

[13] Hargrave, T. J. and Van de Ven, A. H. "A Collective Action Model of Institutional Innovation", Academy of Management Review (31:4), 2006, pp. 864-888.

[14] Henfridsson, O. and Lindgren, R. "Multi-Contextuality in Ubiquitous Computing: Investigating the Car Case through Action Research", Information and Organization (15:2), 2005, pp 95-124.

[15] Hevner, A. "A Three Cycle View of Design Science Research", Scandinavian Journal of Information Systems (19:2), pp. 87-92.

[16] Hevner, A. R., March, S. T., Park, J. and Ram, S. "Design Science in Information Systems Research", MIS Quarterly (28:1), 2004, pp. 75-105.

[17] Klein, H. K. and Myers, M. D. "A Set of Principles for Conducting and Evaluating Interpretive Field Studies in Information Systems". MIS Quarterly (23:1), 1999, pp. 6793. 
[18] Lindgren, R., Andersson, M. and Henfridsson, O. "Multi-Contextuality in Boundary-Spanning Practices", Information Systems Journal (18:5), 2008, pp. 641-661.

[19] Lindgren, R., Henfridsson, O. and Schultze, U. "Design Principles for Competence Management Systems: A Synthesis of an Action Research Study", MIS Quarterly (28:3), 2004, pp 435-472.

[20] Malhotra, A., Gosain, S. and El Sawy, O. A. "Leveraging Standard Electronic Business Interfaces to Enable Adaptive Supply Chain Partnerships", Information Systems Research (18:3), 2007, pp. 260-279.

[21] Markus, M. L., Majchrzak, A., and Gasser, L. 2002. “A Design Theory for Systems That Support Emergent Knowledge Processes", MIS Quarterly (26:3), 2002, pp. 179. 212.

[22] Markus, M. L., Steinfield, C. W., Wigand, R. T., and Minton, G. "Industry-Wide Information Systems Standardization as Collective Action: The Case of the U.S. Residential Mortgage Industry", MIS Quarterly (30:Special Issue), 2006 pp. 439-465.

[23] Melville, N. P. "Information Systems Innovation for Environmental Sustainability”, MIS Quarterly (34:1), 2010, pp. 1-21.

[24] Mårtensson, P. and Lee, A. S. "Dialogical Action Research at Omega Corporation", MIS Quarterly (28:3), 2004, pp. 507-536.

[25] Nalebuff, B. F., and Brandenberger, A. M. "CoOpetition”, London: Harper Collins, 1996.

[26] Sein, M. K., Henfridsson, O., Purao, S., Rossi, M. and Lindgren, R. "Action Design Research", MIS Quarterly (35:1), 2011, pp. 37-56.

[27] Steinfield, C. W., Markus, M. L. and Wigand, R. T. "Exploring Interorganizational Systems at the Industry Level of Analysis: Evidence from the US Home Mortgage Industry", Journal of Information Technology (20), 2005, pp. 224-233.

[28] Street, C. T. and Meister, D. B. "Small Business Growth and Internal Transparency: The Role of Information Systems", MIS Quarterly (28:3), 2004, pp. 473-506.

[29] Susman, G. and Evered, R. "An Assessment of the Scientific Merits of Action Research", Administrative Science Quarterly (23), 1978, pp. 582-603.

[30] Tsai, W. "Social Structure of 'Coopetition' Within a Multiunit Organization: Coordination, Competition, and Intraorganizational Knowledge Sharing", Organization Science (13:2), 2002, pp. 179-190.
[31] Van de Ven, A. H. "Running in Packs to Develop Knowledge-Intensive Technologies", MIS Quarterly (29:2), 2005, pp. 365-378.

[32] Walley, K. "Coopetition: An Introduction to the Subject and an Agenda for Research", International Studies of Management and Organization (37:2), 2007, pp. 11-31.

[33] Walls, J. G., Widmeyer, G. R., and El Sawy, O. A. "Building an Information Systems Design Theory for Vigilant EIS", Information Systems Research (3:1), 1992, pp. 36-59.

[34] Walsham, G. "Interpretive Case Studies in Is Research: Nature and Method", European Journal of Information Systems (4), 1995, pp. 74-81.

[35] Wigand, R. T., Steinfield, C. W. and Markus, L. M. "Information Technology Standards Choices and Industry Structure Outcomes: The Case of the U.S. Home Mortgage Industry", Journal of Management Information Systems (22:2), 2005, pp. 165-191.

[36] Watson, R. T., Boudreau, M. C. and Chen, A. J. "Information Systems and Environmentally Sustainable Development: Energy Informatics and New Directions for the IS Community", MIS Quarterly (34:1), 2010, pp. 23-38.

[37] Watson, R. T., Boudreau, M-C., Chen, A. J. and Sepúlveda, H. H. "Green Projects: An Information Drives Analysis of Four Cases", Journal of Strategic Information Systems (20: Special Issue), 2011, pp. 55-62.

[38] Yoo, Y., Lyytinen, K. and Yang, H. "The Role of Standards in Innovation and Diffusion of Broadband Mobile Services: The Case of South Korea", Journal of Strategic Information Systems (14), 2005, pp. 323-353. 